\title{
1
}

\section{A Stepped Approach to Generating a Single Set of RTK Parameters for Continuous Calibration}

\section{Hazem Gheith}

This chapter presents a straightforward approach to generating a constant, single set of RTK parameters per monitored sewershed which provides good wet weather flow (WWF) continuous simulation for all monitored storm events. This single set is function of collection system deterioration conditions and sewershed physical dimensions, which are constant in each monitored basin. A constant single set of RTK parameters which successfully regenerates observed WWF responses from all monitored storm events will ensure accurate flow prediction when applied to non-monitored periods. The difficulty in calculating a single set of RTK parameters comes from the lack of knowledge of how much initial abstraction is available at the start of each storm event. Initial abstraction refers to the amount of rainfall that will be lost to wet the surface and subsurface before the excess rain (runoff) arrives to the receiving collection system. The stepped approach presented in this chapter resolves this difficulty since it relies on selecting a monitored storm event where the initial abstraction is almost negligible. This can be achieved by selecting a monitored storm event which was shortly preceded by another large storm. The first storm will bring the sewershed into a saturated condition. The period between the two storms should be short to avoid large recovery of the system storage. This saturated condition will ensure that most of the second storm's rain is runoff since the initial abstraction term in the $R$-equation is negligible. Generating $R$ based on this second storm event will allow $R$ to be almost exclusively a function of the

Gheith, H. 2010. "A Stepped Approach to Generating a Single Set of RTK Parameters for Continuous Calibration." Journal of Water Management Modeling R236-01. doi: 10.14796/JWMM.R236-01.

(C) CHI 2010 www.chijournal.org ISSN: 2292-6062 (Formerly in Dynamic Modeling of Urban Water Systems. ISBN: 978-0-9808853-3-0) 
collection system's size and asset defects and not affected by initial abstractions. Similarly, in a saturated condition, the $T$ and $K$ parameters will not be affected by delay time to wet the surface and subsurface storages. The constant, single set of RTK parameters from that storm represents the collection system response to runoff. To accurately introduce the effect of initial abstraction between the storm events, values of the storage recovery rate parameter should then be adjusted to account for climatic change conditions.

The proposed approach was successfully used to characterize WWF conditions in the West Fifth Avenue Sanitary Sewer System Inflow and Infiltration Remediation Project in the city of Columbus, Ohio. Sixty flow meters were used to monitor the flow response from the basin's sewersheds. Monitoring activities were conducted between August 2007 and June 2008. Monitored tributary sewershed areas varied in size from $<10$ acres ( 4 ha) to $>300$ acres (121 ha). A constant, single set of RTK parameters was generated for each monitored sewershed following the proposed stepped approach. Recovery rates and maximum storage were adjusted monthly to allow for climatic and groundwater changes. The generated RTK sets accurately simulated WWF responses in each monitored sewershed for all year-long monitored storm events. The generated single set of RTK parameters closely described the collection system's deterioration condition. It can be applied to non-monitored and synthetic design storms with confidence and will ultimately lead to more accurate recommendations and sizing for capital improvement projects.

\subsection{Continuous Calibration}

Continuous simulation facilitates the evaluation of a collection system over annual or longer periods. Several factors affect the amount of flow intercepted into a sanitary collection system. These factors include amount and configuration of the defects in the collection system network, the size of the collection system sewershed, the total precipitation, and the climatic conditions prior and during the storm event. A hydrology model that could confidently be used to evaluate the collection system response is the one where the real field conditions are closely represented with clear physical representation.

Understanding collection system performance under a variety of storm levels and durations is important to both regulatory agencies and sanitary authorities. For regulatory agencies, it allows for quantifying frequency, volume and duration of overflows, and understanding water quality impacts on receiving waters. For sanitary authorities, this understanding helps ensure that 
capital improvements for system mitigation are not overly conservative, thereby reducing costs and billing rate increases.

\subsubsection{Event-basis Calibration versus Continuous Calibration}

In most sanitary collection systems, rain dependent inflow and infiltration (RDII) is the driving force for surcharge conditions and sanitary sewer overflow (SSO) incidents. Simulating the mechanism of how RDII is generated is the key for a successful understanding of the collection system hydraulics during WWF conditions. There are several methodologies to model RDII generation in hydraulic models. A detailed overview of RDII prediction methodologies is presented by Vallabhaneni et al. (2007) and Lai (2008). Hydrology and hydraulics models can be calibrated based on event-basis calibration or on continuous calibration. Historically, event-basis calibration protocol was dominant. To perform event-basis calibration, several models are generated from monitored wet weather events. Based on the availability of flow data and the focus of the study, a number of historical storms representing different levels and durations are selected. Each historical storm is calibrated for in a separate model. It is recognized that RDII parameters in each model will be different since each model is independently calibrated to match the individual storm. Based on the design storms to be evaluated, the model in which the historical storm characteristics are closest to the design storm is used for the evaluation.

There are some problems with the event-based method. First, the generation of these several independent calibrated models is time consuming. Secondly, due to the limitation on the number and variety of storm events during the flow monitoring period, limited types of storm characteristics are calibrated for. When studying a non-monitored storm event or when using a design storm with a duration or level that does not match the calibrated models, the certainty of the results is unclear. Finally, and most troublesome, calibrating historical events, independently without accurate consideration for the effect of antecedent moisture conditions between the storm events could lead to over or under estimating flow response to storm events. This is due to the difficulties to determine and account for appropriate initial abstraction at the start of each event selected for calibration. Initial abstraction is the amount of rainfall that will be used to wet the surface and fill surface and subsurface storages before portion of the remaining runoff could be intercepted into the sanitary collection system.

Continuous simulation allows for studying the system response to a variety of storm conditions. It allows for accounting for initial abstraction between the events in the continuous simulation. In the U.S mid-west, approximately 100 
storm events annually take place with varying durations and intensities. In prolonged dry period conditions, system storages (such as ponds, vegetation or groundwater) become extremely dry. When rainfall events take place, much of the precipitation will be used to wet the ground before a runoff will take place. However when one storm almost immediately follows another storm, the later storm will fall on saturated ground, leading to higher runoff response. Peak and volume of the RDII observed in the sanitary sewers will vary accordingly. For example, Figure 1.1 shows a monitored RDII response to a series of large storm events that took place in June 2008 in one sewershed in the city of Columbus, Ohio. The events on June 3-4, 2008 took place after a prolonged dry period $(13 \mathrm{~d})$ while the event on June 12, 2008 took place approximately $2 \mathrm{~d}$ after the event on June 10. Total rainfall volume in June 3-4 events was 2.35 in. $(60 \mathrm{~mm})$ while total rainfall in June 12 event was 1.95 in. $(50 \mathrm{~mm})$. The total RDII volume in each event is approximately $0.3 \mathrm{MG}\left(1135 \times 10^{6} \mathrm{~L}\right)$ and $0.6 \mathrm{MG}\left(2271 \times 10^{6} \mathrm{~L}\right)$, respectively. Although both rainfall events took place over the same collection system and were monitored at the same point, RDII into the collection system varied significantly. The RDII volume from the lower total rainfall event (June 12) was double the RDII volume from the larger total rainfall event (June 4). The defects and cracks in the collection system (represented in $R$-value) did not change. As well, the travel time it takes for inflows and groundwater infiltration to reach the collection system (represented in SWMM by the two parameters $T$ and $K$ ) did not change. The difference is that the antecedent moisture conditions varied dramatically between the two events. For the June 4 event, the ground was dry whereas for the June 12 event, the ground was very wet. This is the reason that the collection system responded so differently for the June 4 event than for the June 12 event. Appropriate initial abstraction in each event should first be subtracted from the precipitation before a comparison in RDII can be concluded.

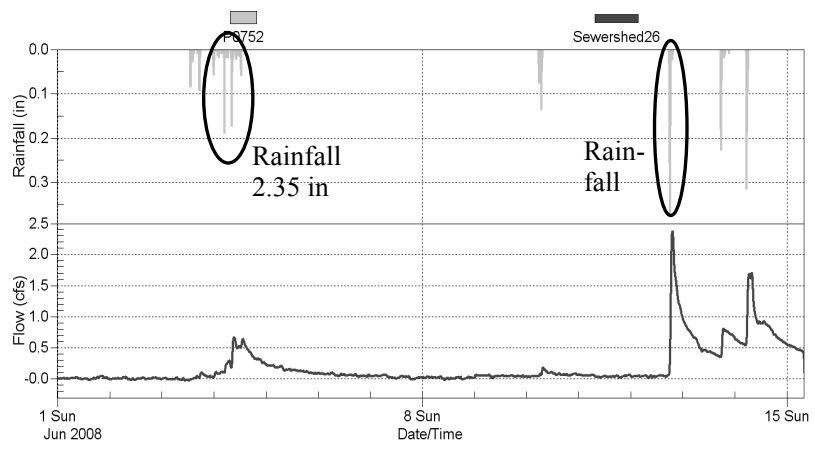

Figure 1.1 Initial abstraction effect on RDII volume. 
In a continuous simulation process, a hydrology and hydraulic model will allow for the initial abstraction as function of the antecedent moisture condition (AMC) to automatically be calculated before calculating RDII response. The challenge becomes to define a stepped, time efficient procedure to generate the single set of RTK parameters that is not a function of the climatic conditions, which, if paired with the appropriate abstraction calculations, can be used to simulate, with confidence, RDII response from any type of storm and under any AMC.

\subsubsection{Continuous Calibration Methodologies}

Several methodologies in the literature have been proposed to simulate RDII responses in the collection system. Some of these methodologies are not SWMM-based techniques while others are based on SWMM engine to calculate RDII responses. Davis and Merrill (1999) introduced an approach where the RDII response is calculated using a regression model as shown in Figure 1.2 .

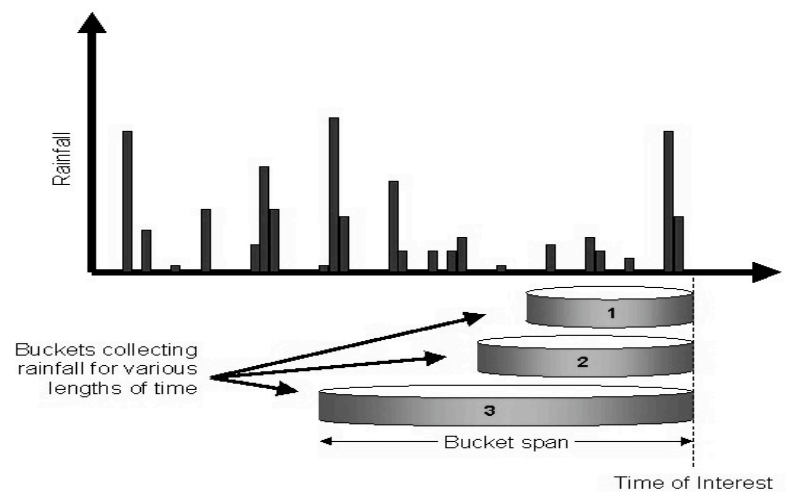

Figure 1.2 Regression (bucket theory) model in calculating RDII response.

It can be thought of as a number of theoretical buckets collecting rain. Each of the buckets collects rain over a specific length of time, which is called the bucket span. The regression model is based on the theory that RDII at any particular moment is proportional to the amount of rainfall in each of the buckets at that same instant. The proportional relationship is governed by a constant coefficient specific to each bucket that must be determined by the user. In addi- 
tion to setting the bucket coefficients, the user can specify a lag time for the buckets. This lag time effectively delays the arrival of flow from the buckets. The method indirectly accounts for the initial abstraction through the amount of rain accounted for over the bucket spans.

Davis and Merrill also developed a more detailed continuous calibration model based conceptually on the Stanford watershed model and the generalized watershed loading function model. A conceptual diagram of the model is shown in Figure 1.3. As shown in the figure, a set of parameters is used to describe the storm water distribution over pervious and impervious surface of the sanitary sewershed. Percentage distribution of these parameters is obtained numerically using genetic algorithm calibration technique. Czachorski (2006) introduced an optimization tool, the antecedent moisture model. The model is based on system identification techniques borrowed from aerospace control systems and digital signal processing. In his technique, Czachorski integrated rain data, temperature, and time between events into the optimization protocol to calibrate for the two RDII components: inflow and infiltration.

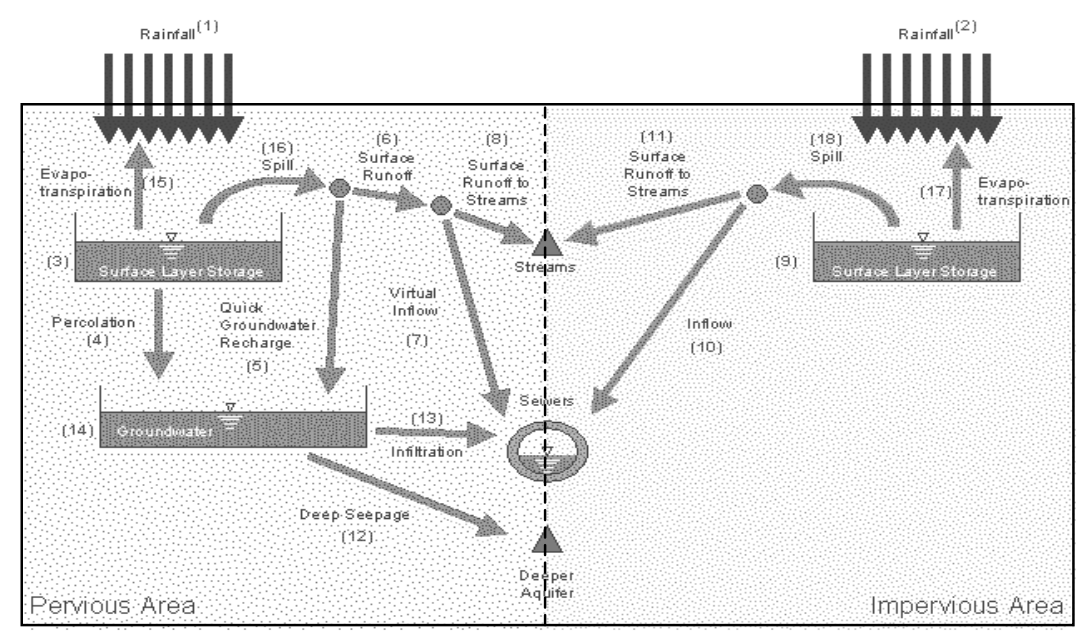

Figure 1.3 Generalized watershed loading function model in calculating RDII response.

RDII can be calculated in SWMM using the unit hydrograph technique, also known as the RTK Method. The method was included as an option in the SWMM Runoff block (Huber and Dickenson, 1988). In this method, the RDII response is calculated from the runoff (after subtracting initial abstraction from 
rainfall). RDII from one unit of rain is assumed to be a triangle. The triangles are defined by time-to-peak, $T$, and the ratio of recession limb to time-to-peak, $K$ so that the time base is $T \times(1+K)$. The area of the triangle is $R$, which is the percentage of RDII volume from the excess rain (runoff), from which peak flow can be calculated. Up to three triangles are usually used to describe the RDII. The first triangle, usually referred to as the inflow portion, represents the fast response from direct runoff from foundation drains, downspouts and other types of direct connections. The second triangle represents the delayed response from near surface defects like cracked manholes, or near-surface private later connections with cracks and defects. The third triangle represents the delayed response from increased groundwater level causing infiltration from pipe cracks, defected pipe joints, and damages due to pipe sagging or root intrusions. Figure 1.4 presents the theory of the RTK parameters.

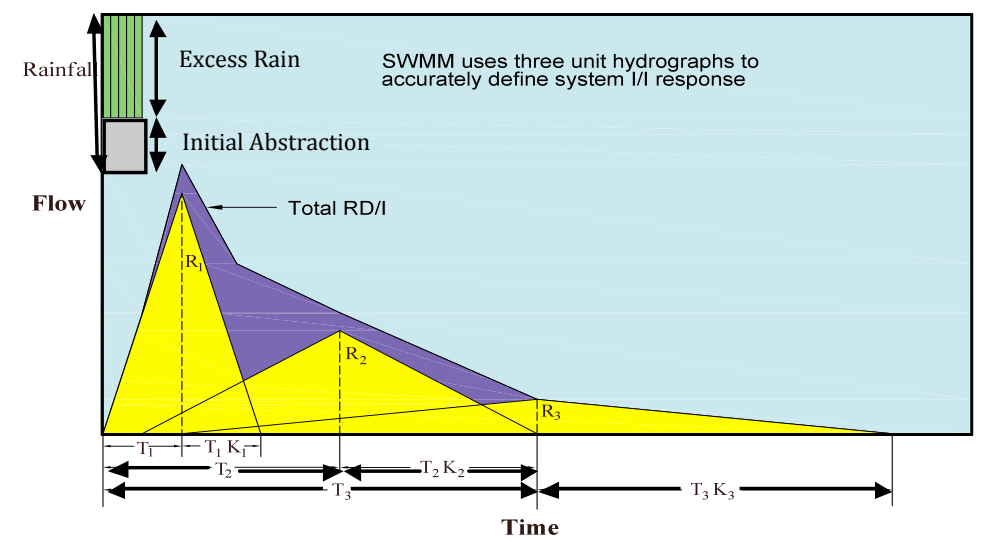

Figure 1.4 RTK procedure in calculating RDII response. $R$ is the percentage of excess rain that enters the collection system through system defects. Excess rain is calculated after subtracting the initial abstraction.

The RTK method was originally used to simulate RDII response from individual storms. Calculating excess rain (runoff) was achieved by introducing initial abstraction parameter, a user-defined input. In order to facilitate the collection system evaluation process under a variety of storm events in a continuous simulation, a storage recovery rate between storms was introduced. For continuous simulation, SWMM engine allows for defining a recovery rate for each simulated month. 


\subsection{SWMM RDII Parameters Calibration Practices}

In SWMM RTK method, $T$ and $K$ reflect the delay time before RDII enters the collection system and are function of the sewershed dimensions. The $R$ value is the percentage of runoff volume that enters the system through the cracks and system defects. The runoff is calculated after subtracting initial abstraction from the precipitation. Although total rain is known from rain gauges, runoff is difficult to calculate at the beginning of each storm event due to the difficulty in calculating initial abstraction. In this section, current practices for RDII calculations in SWMM will be reviewed followed by discussions of current RDII parameters calibration practices and limitations.

\subsubsection{AMC Considerations in RDII Parameters Calibration}

As previously mentioned, SWMM engine allows users to provide several parameters to facilitate calculating RDII volume and peak flow at each time step. In the RTK method, three triangles are used to generate RDII from runoff as shown in Figure 1.4. Equation 1.1 summarizes RDII volume calculations from the three triangles at the beginning of each rain event in a continuous simulation:

$$
R D I I_{\text {Volume }}=\sum_{j=I}^{3} R D I I_{j}=\sum_{j=1}^{3} R_{j} \times\left(i_{\text {total rain }}-I_{a j}\right) \times A_{\text {serviced }}
$$

where:

$$
\begin{aligned}
R= & \text { Percentage of runoff (excess rain) entering the } \\
& \text { collection system as RDII. The } R \text { parameter is a user- } \\
& \text { defined parameter and is function of size and number } \\
& \text { of defects. Theoretically, } R \text { will be zero for tight } \\
& \text { portions of the collection system regardless of the } \\
& \text { precipitation volume and climatic conditions. } R \\
& \text { increases when number of pipe defects increase; } \\
i_{\text {total rain }=} & \text { Precipitation data from rain gauges; } \\
I_{a}= & \text { Initial abstraction at the beginning of each storm event. } \\
& \text { This is calculated by SWMM in continuous simulation } \\
& \text { based on the number of dry (no rain) days between the } \\
& \text { storm events. In event basis calibration, this parameter } \\
& \text { is user-defined; and } \\
A_{\text {serviced }}= & \text { Serviced portion of the sanitary sewershed area } \\
& \text { upstream from the flow meter. Only the area expected }
\end{aligned}
$$


to contribute to RDII should be considered. This is also a user-defined value which can be obtained using GIS or aerial maps with knowledge of collection system distribution (public and private sewers).

The effect of AMC in Equation 1.1 is put into one parameter, $I_{a}$. The initial abstraction is incrementally accumulated at each dry (no rain) time step. It varies between zero at completely saturated conditions (no available storage) to a maximum abstraction value after a prolonged dry weather conditions. This maximum abstraction value $\left(S_{\max }\right)$ is called maximum storage. $S_{\max }$ is a user defined parameter which is a function of sewershed topography, slope, vegetation, and groundwater table level. The user also defines a storage recovery rate. The initial abstraction $I_{a}$ is then calculated in SWMM as described in Equations 1.2 and 1.3 .

$$
\begin{aligned}
& I_{a}=n_{\text {dry days }} \times \operatorname{Rec} \\
& 0 \leq I_{a} \leq S_{\text {max }}
\end{aligned}
$$

where:

$n_{\text {dry days }}=$ number of dry days before the storm event; and

$R e c=$ user-defined storage recovery rate (in./d).

\subsubsection{Practices in Defining $R$ and $I_{a}$}

Equation 1.1 can be rearranged to calculate for $R$ as follows:

$$
R=\frac{R D I \text { Volume }}{A_{\text {serviced }} \times\left(i_{\text {total rain }}-I_{a}\right)}
$$

In Equation 1.4 above, $R D I I_{\text {volume }}$ and $i_{\text {total rain }}$ are known from flow meter and rain gauge data. $A_{\text {Serviced }}$ is known from GIS or aerial maps. Equation 1.4 then has two unknowns, $R$ and $I_{a}$. Accurate calculation for $R$ is hindered by the lack of knowledge for $I_{a}$. Table 1.1 describes the possible practices in defining the two unknowns $R$ and $I_{a}$ in Equation 1.4. 
Table 1.1 Practices in defining $l_{a}$ and $R$.

\begin{tabular}{|c|c|c|c|}
\hline Practice & $I_{a}$ & $R$ & Comments \\
\hline 1 & Constant & Variable & $\begin{array}{l}\text { In this practice, } I_{a} \text { is kept constant. The AMC effects } \\
\text { will be embedded in } R \text { when solving Equation 1.4. }\end{array}$ \\
\hline 2 & Constant & Constant & $\begin{array}{l}\text { In this practice, both } I_{a} \text { and } R \text { are kept constant. The } \\
\text { AMC effects will be embedded in } R \text { when solving } \\
\text { Equation 1.4. Starting with a constant } I_{a} \text {, an } R \text { value is } \\
\text { calibrated for from each storm. An average or median } \\
R \text { value is then calculated from all calibrated events. }\end{array}$ \\
\hline 3 & Variable & Variable & $\begin{array}{l}\text { In this practice, both } I_{a} \text { and } R \text { vary. The AMC effects } \\
\text { will be embedded and split in both } I_{a} \text { and } R \text { when } \\
\text { solving Equation } 4 \text {. The practice is used in event-basis } \\
\text { calibration. }\end{array}$ \\
\hline 4 & Variable & Constant & $\begin{array}{l}\text { In this practice, AMC effects will be accounted for } \\
\text { through } I_{a} \text {, which varies between the events due to } \\
\text { changes in climate conditions. } R \text { is kept constant as a } \\
\text { function of the number and size of defects. This } \\
\text { practice is the most close to field conditions. This } \\
\text { chapter provides a stepped procedure to implement } \\
\text { this practice in SWMM. }\end{array}$ \\
\hline
\end{tabular}

\section{Practice 1: $\mathrm{I}_{\mathrm{a}}$ is Constant, $\mathrm{R}$ Varies}

This practice is usually used in studying one event at a time (event-basis calibration). Since $I_{a}$ is kept constant, the AMC effects will be embedded in $R$ when solving Equation 1.4 above. Accordingly, values calculated for $R$ in each event will vary since AMC varies from one event to another. Figure 1.5 presents calibration results for a monitored basin in the City of Columbus West Fifth I/I Study. Six models were created and calibrated for six events that took place in the first two weeks of June 2008. Flow monitoring was conducted to a 305 acre (124 ha) sewershed. The initial abstraction is held constant for each of the calibrated events. The RTK parameters for each model are presented in Table 1.2. The time parameters, $T$ and $K$, are held constant. Both peak RDII and RDII volume for each calibrated event had $<1 \%$ difference from the observed data.

Table 1.2 RTK parameters for the six models calibrated for the six events of June 2008.

\begin{tabular}{cccccccccccc}
\hline Date & Area & $T_{1}$ & $T_{2}$ & $T_{3}$ & $K_{1}$ & $K_{2}$ & $K_{3}$ & $R_{1}$ & $R_{2}$ & $R_{3}$ & $R_{\text {total }}$ \\
\hline 03-Jun & 305 & 0.033 & 2 & 4 & 120 & 7 & 10 & 0.0115 & 0.0100 & 0.0140 & 0.0355 \\
04-Jun & 305 & 0.033 & 2 & 4 & 120 & 7 & 10 & 0.0255 & 0.0110 & 0.0470 & 0.0835 \\
10-Jun & 305 & 0.033 & 2 & 4 & 120 & 7 & 10 & 0.0155 & 0.0095 & 0.0300 & 0.0550 \\
12-Jun & 305 & 0.033 & 2 & 4 & 120 & 7 & 10 & 0.0410 & 0.0300 & 0.0700 & 0.1410 \\
13-Jun & 305 & 0.033 & 2 & 4 & 120 & 7 & 10 & 0.0230 & 0.0030 & 0.1000 & 0.1260 \\
14-Jun & 305 & 0.033 & 2 & 4 & 120 & 7 & 10 & 0.0350 & 0.0390 & 0.1000 & 0.1740 \\
\hline
\end{tabular}



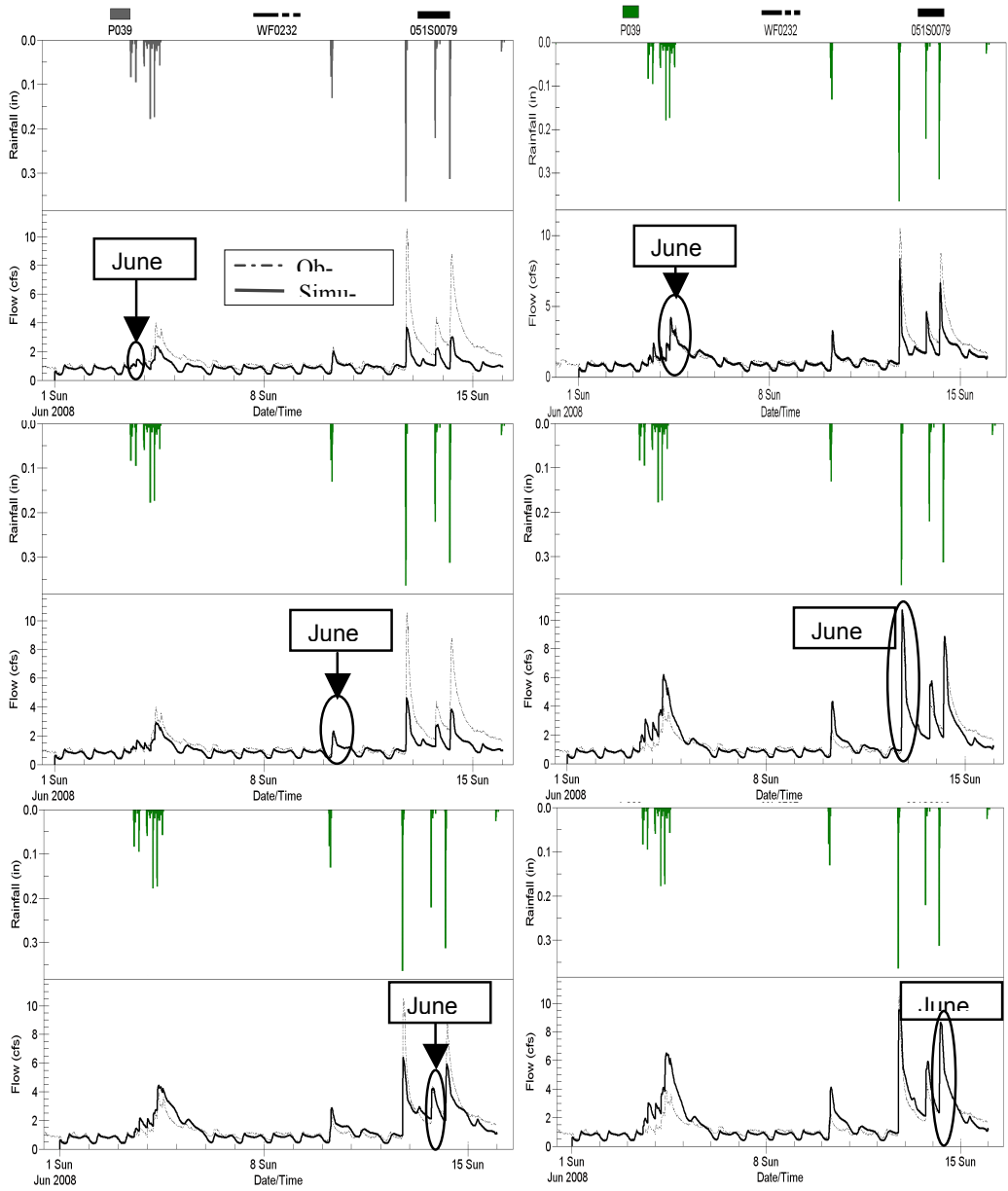

Figure 1.5 Calibration results for each of the six models used to calibrate the six storm events took place in June 2008. Light dashed lines are the observed flow hydrograph. Think dark lines are the simulated hydrograph results.

This practice is not suitable for a continuous simulation since each RTK set of parameters is event specific. To illustrate the deficiency in using this method for continuous simulation, each model was run for the two weeks in June, 2008 in an attempt to validate each set of the RDII parameters. As shown in Figure 1.5 above, simulation of each calibrated model to the other five storm events 
resulted in errors in both peak RDII and RDII volume. The errors ranged from $\pm 10 \%$ to $\pm 300 \%$.

\section{Practice 2: $\mathrm{I}_{\mathrm{a}}$ and $\mathrm{R}$ are Constant}

In this practice, an average or most likely value for both $I_{a}$ and $R$ are calculated. One method to calculate $I_{a}$ and $R$ is to plot Equation 1.1 above with $i_{\text {total rain }} \mathrm{x}$ $A_{\text {serviced }}$ as the $x$-axis and RDII volume as the $y$-axis. Each event will be represented by a point in the scattered graph. The regression line will then have a slope equal to $R$ and the intersection with the negative $y$-axis will be $R \times I_{a}$. Limitation of this method is that $I_{a}$ is forced to be constant. The points in the graph will be widely scattered since RDII volume could change dramatically for events with same $i_{\text {total rain }}$ as was shown in Figure 1.1 above, for example.

Another method that has been practiced in modeling collection systems with keeping constant values for $I_{a}$ and $R$ for all events is by fixing $I_{a}$ equal to a constant value and then use all monitored events for calculating an average or median $R$. This method is tested using the calibration example from Practice 1 above in which $I_{a}$ is assumed zero and six events were calibrated for RTK values as shown in Table 1.2 above. The average and median values for RTK parameters are shown in Table 1.3. The median $R$-values were used to simulate RDII as shown in Figure 1.6.

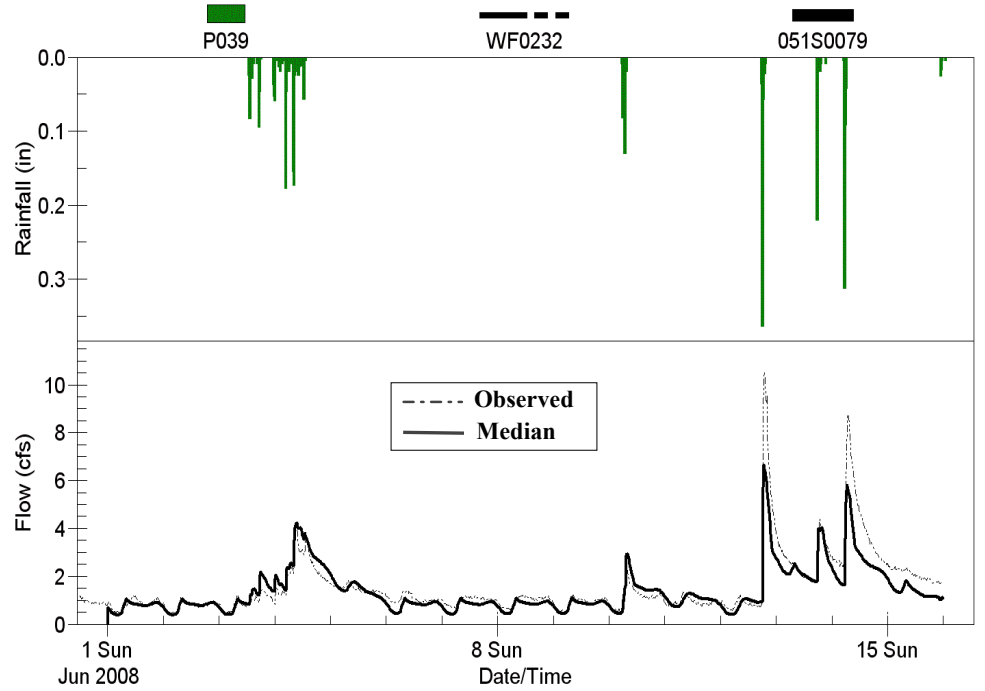

Figure 1.6 RDIl prediction using a constant $l_{a}$ and median $R$ values from Table 1.3. 
Table 1.3 Median and average RDII parameters for the six events presented in Table 1.2 above.

\begin{tabular}{cccccccccccc}
\hline \multicolumn{1}{c}{ Date } & Area & $\mathrm{T}_{1}$ & $\mathrm{~T}_{2}$ & $\mathrm{~T}_{3}$ & $\mathrm{~K}_{1}$ & $\mathrm{~K}_{2}$ & $\mathrm{~K}_{3}$ & $\mathrm{R}_{1}$ & $\mathrm{R}_{2}$ & $\mathrm{R}_{3}$ & $\mathrm{R}_{\text {total }}$ \\
\hline Median & 305 & 0.033 & 2 & 4 & 120 & 7 & 10 & 0.0243 & 0.0105 & 0.0585 & 0.0933 \\
\hline Average & 305 & 0.033 & 2 & 4 & 120 & 7 & 10 & 0.0253 & 0.0171 & 0.0602 & 0.1025 \\
\hline
\end{tabular}

As seen in Figure 1.6, simulated and observed flows are close in some events. At some events (June 12 and June 14) the simulated peak RDII and RDII volume is off by almost $50 \%$. It is clear that this method leads to constant values for $I_{a}$ and $R$ that are not adequate for continuous simulation. Adequacy of simulated RDII using this median set of RTK parameters in non-calibrated storm events is unclear and could lead to under over prediction of true system response to the storm events.

\section{Practice 3: Both $\mathrm{I}_{\mathrm{a}}$ and $\mathrm{R}$ Vary}

This practice is sometimes used in event-basis calibration technique. Each event is calibrated independently with $I_{a}$ used as one of the calibration parameters to be estimated for each event. Accordingly, for each event to be calibrated, $I_{a}$ and $R$ values calculated for each event can be arbitrary as long as the combination between the two values works together to satisfy Equation 1.4 above. Traditionally, three calibration events are selected from the monitored events to cover short, medium and long duration and high return frequency storms. When validating the model or using the model to study a non-monitored storm event, the calibrated hydrology model that is closest to the non-monitored storm is used.

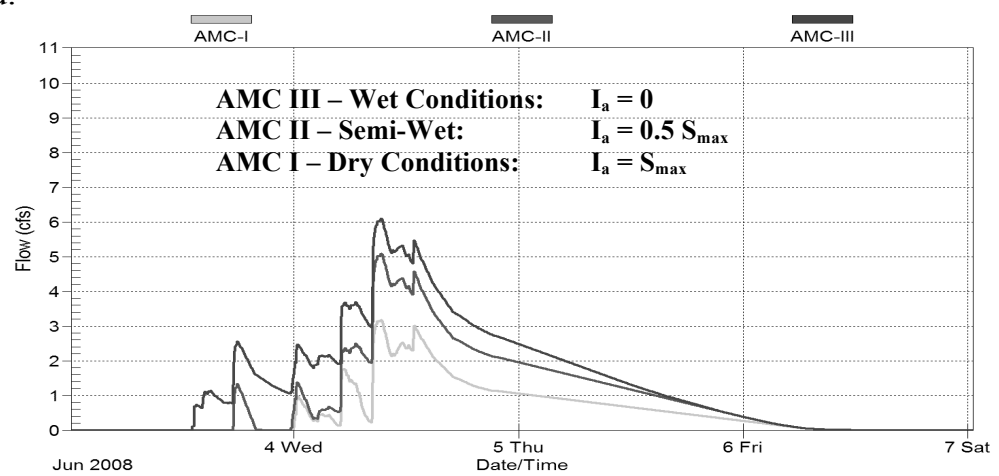

Figure 1.7 Effect of AMC on RDII response for dry, semi-wet and saturated floor conditions one day before the rain event. 
This practice is not suitable for continuous simulation since not knowing the true $\underline{I}_{a}$ at the start of each storm could mislead the RDII prediction. For example, using the model calibrated previously for the June 4, 2008 event, Figure 1.7 above shows the evaluation results to predict RDII response assuming three AMC: dry, semi wet, and saturated.

As shown in Figure 1.7, a dry AMC resulted in the lowest RDII peak flow and volume, while a completely saturated AMC resulted in doubling RDII peak flow and volume. It can easily be concluded that AMC effect could excessively change the outcome of the system response, which in turn could lead to over- or under-estimated sizes of capital improvement. This also shows the importance for planners who use design storms to evaluate collection system conditions should also define proper basins saturation conditions as part of the evaluation plan. This is one of the main reasons why a continuous calibration is becoming more preferred.

\section{Practice 4: $\mathrm{I}_{\mathrm{a}}$ Varies, $\mathrm{R}$ is Constant}

This practice is the preferred approach for continuous simulation as it is considered to be the best representation of actual field conditions. As previously noted, the $R$ value is the percentage of runoff volume that enters the system through the cracks and system defects. These defects are not seasonal and are not event-related. The value for $I_{a}$ is variable based on climatic conditions, and is calculated at the beginning of each storm event. $I_{a}$ is calculated internally in SWMM utilizing the SWMM user-defined storage recovery rate parameter. Figure 1.8 presents calibration results for the same meter location tested in Figure 1.6 above. A one value for the storage recovery rate $(R e c)$ was adjusted to allow SWMM engine to recalculate $I_{a}$ at the start of each storm event based on the number of dry days between the events. A starting value can be calculated based on minimum storm precipitation where RDII response was observed in the metered data. Calibration results in Figure 1.8 between simulated and observed peak flows and RDII volume are good. Comparison between results from practices 2 and 4 is presented in Figure 1.9. The calibration results demonstrate the valuable usage of the storage recovery rate to calculate $I_{a}$ while maintaining a constant $R$. Stepped approach for applying this practice is presented in the following section. 


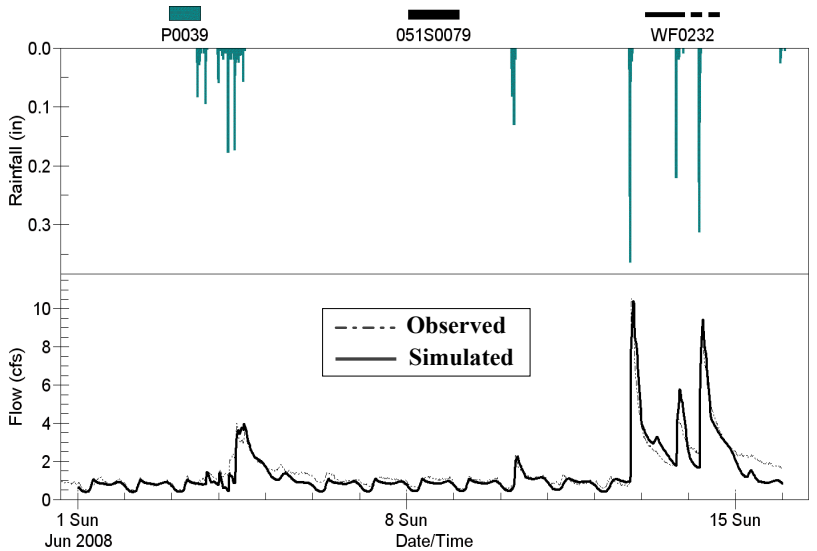

Figure 1.8 RDII prediction using a constant RTK set of parameters. The initial abstraction at the start of each storm , $l_{a}$, is recalculated by the SWMM engine at the start of each of the six events in June 2008 based on number of dry days between the events and using one value for the storage recovery rate (in./d).

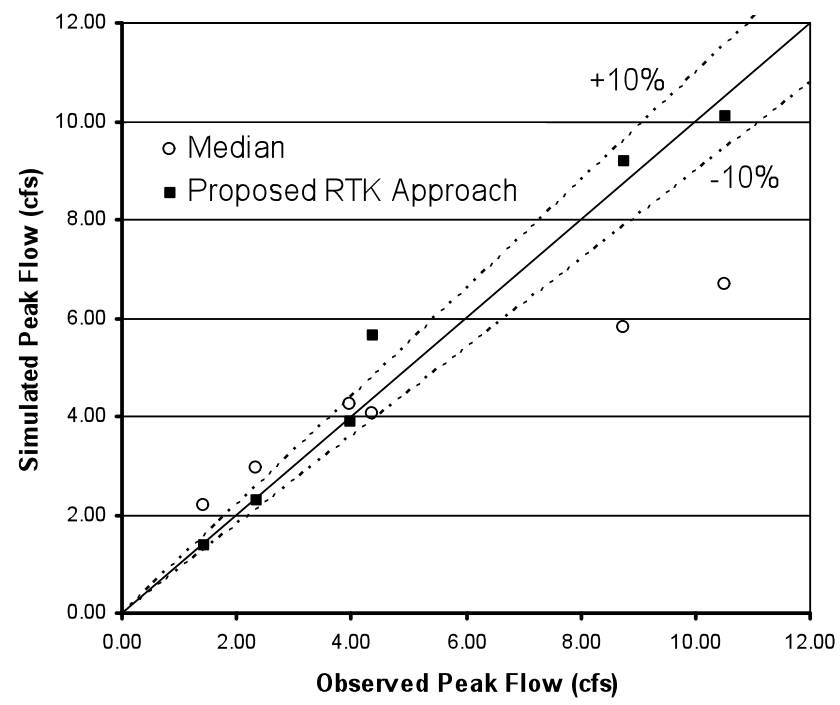

Figure 1.9 Comparison of peak flow results from continuous simulations following practices 2 and 4 . 


\subsection{Proposed Approach for Calculating RDII Parameters for Continuous Calibration}

\subsubsection{Theory}

As discussed in the previous section, practice 4 for defining $R$ and $I_{a}$ is the closest to field conditions. In this practice, $R$ is constant in all events since it is function of system defects, while $I_{a}$ varies from one event to another. Figure 1.10 shows the climatic conditions affecting $I_{a}$. If precipitation takes place over an area serviced by a collection system, a portion of this precipitation will be lost due to wetting the ground, infiltration, evaporation, transpiration, and other types of water storage. The runoff (excess rain) is then collected by the storm system. A portion of this runoff will intrude as RDII into the sanitary collection system through cracks and other system defects. Between storm events, the basin storage will be recovered based on number of dry days between the events and storage recovery rate. The recovered storage before any event (initial abstraction) could be anywhere between zero and the maximum basin storage volume as described in Equation 1.3 above.

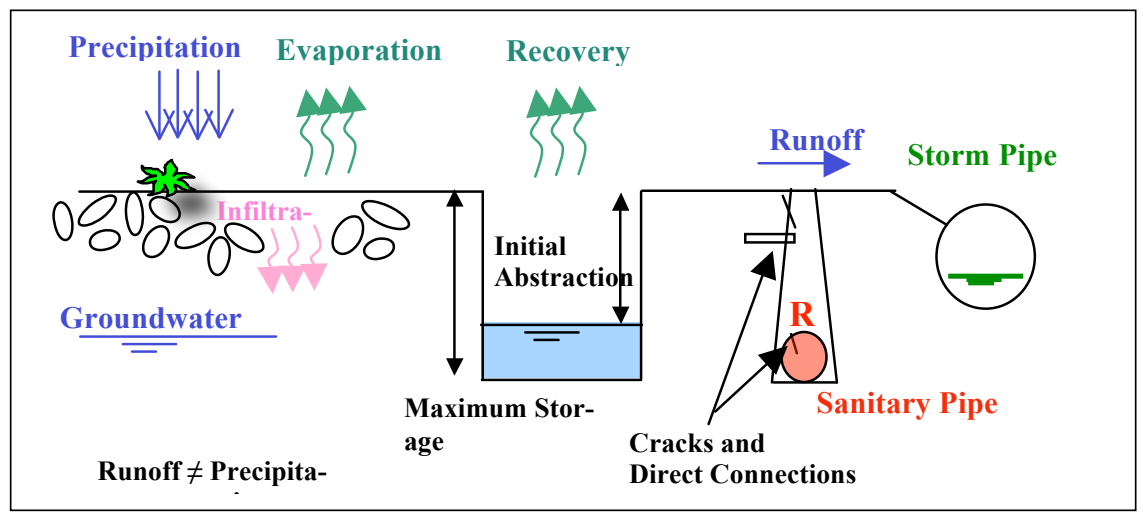

Figure 1.10 Partial saturated condition. $l_{a}$ is function of storage recovery rate, number of dry days, and maximum storage. In this condition, runoff is less than precipitation. Parameters different from one season to another; maximum storage and recovery rate.

The recovery rate is expected to change based on temperature, wind speed, radiation, humidity, and other climatic effects. Also, the maximum basin storage is expected to change seasonally based on groundwater table and 
vegetation. That is why the initial abstraction is highly variable and difficult to calculate. Still, as demonstrated above, ignoring it could mislead attempts to calibrate for an independent set of RTK parameters that regenerate RDII response and are not storm specific

Figure 1.11 represents a saturated floor condition that can take place when there are back-to-back storms. If the system reaches a completely saturated condition during one storm event and another storm event occurs shortly thereafter, precipitation from the second storm will almost entirely become runoff. This is due to the fact that at this condition, $I_{a}$ can safely be assumed zero in Equation 1.4 above. Knowing the total precipitation $\left(i_{\text {total rain }}\right)$ and monitored RDII, $R$ can straightforward be calculated from Equation 1.4 above. Also, $T$ and $K$ can more accurately be calculated from this saturated condition since delay time due to wetting the floor, filling the surface and subsurface voids will be minimal.

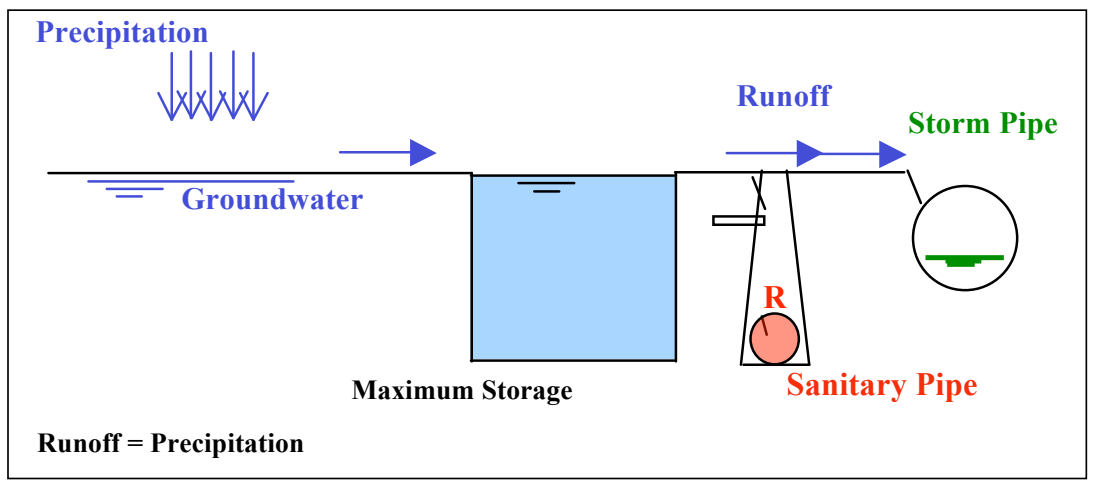

Figure 1.11 Saturated condition. $I_{a}$ is negligible and runoff is almost equal to the precipitation.

\subsubsection{Stepped Procedure}

The procedure for determining the RDII parameters $\left(R, T, K, S_{\max }, I_{a}\right.$, and $\left.\operatorname{Rec}\right)$ can be summarized as follows.

\section{Step 1}

Process rain gauge data and flow meter data to identify storms where the AMC impact on RTK parameters is minimal. The best situation is to have a storm event which is shortly preceded by another large storm. Two examples of this type of situation are presented in Figure 1.12. The target is to find a monitored 
system response where the initial abstraction is negligible and can safely be ignored in Equation 1.4 above. If applicable, an event at times where the groundwater level was high and temperature was low would lead to best results. The high groundwater level will minimize sewershed storage system and the low temperature will reduce evaporation. This will help minimize the effect of storage recovery rate between the events and will keep $I_{a}$ minimal.
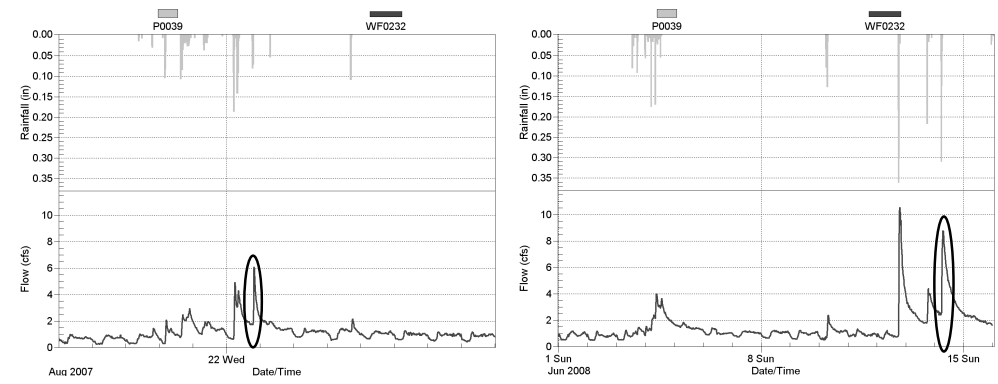

Figure 1.12 Examples of RDIl events where $l_{a}$ is minimal $(\approx 0)$.

Step 2

Since $I_{a} \approx 0$, Equation 1.4 becomes:

$$
R=\frac{R D I I}{A_{\text {serviced }} \times i_{\text {totalrain }}}
$$

Knowing the precipitation, $i_{\text {total rain }}$ from the rain gauges and $R D I I$ volume from the flow meter data for the selected storm event, $R$ can be solved for using Equation 1.5.

\section{Step 3}

Calibrate for $T$ and $K$ to match simulated peak flow and shape to the observed hydrograph.

\section{Step 4}

Use the same RTK in all events of the continuous simulation and apply appropriate maximum storage and storage recovery rate to account for the seasonal effect. SWMM4.4 and SWMM5 allow for monthly value adjustment for the maximum storage and storage recovery rate for each of the three triangles used 
to simulate the three RDII sources. (Note: maximum storage and storage recovery rate for each triangle is available in SWMM4.4 and SWMM5.00.16 and later versions; earlier versions of SWMM5 allow one set of maximum storage and storage recovery rate to be applied to all triangles.)

\subsection{Case Study}

The RDII practice proposed in this chapter was applied to the City of Columbus West Fifth Avenue I/I study. The study area is approximately 1100 acres (447 ha). Additionally, 380 acres (155 ha) within Upper Arrington are flowing into the study area at four connection points as shown in Figure 1.13. The area also receives relief flow from Grandview Heights as indicated in the figure. The sanitary collection system in the study area discharges at three outfall locations.

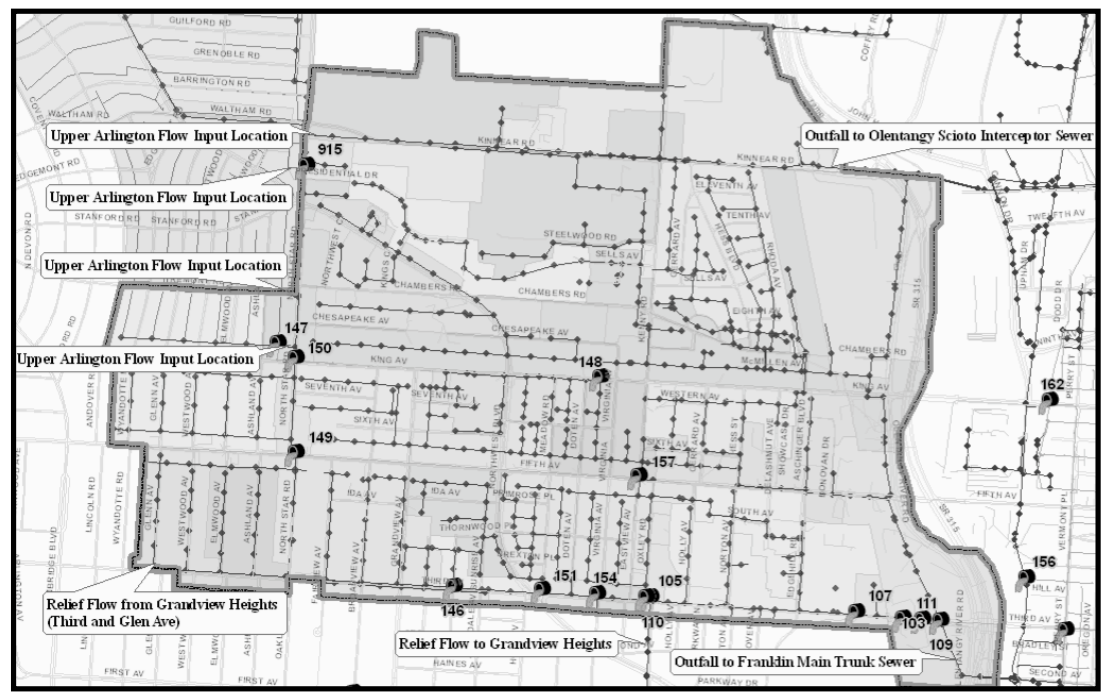

Figure 1.13 West Fifth Avenue I/I study area.

When the sanitary collection system is surcharged, fifteen designed sanitary relief connections at key manholes allow the system to relieve to the storm collection system. A total of 60 flow monitors were placed in the study area for almost one year. Eight meters were placed to monitor flow discharging into and from the study area. Fifteen meters were used to monitor the overflows. The remaining meters were strategically placed to facilitate RDII evaluation and 
model calibration. Two rain gauges were placed within the study area. The new model was built using GIS and survey data. All pipes were cleaned and televised. The new model included all 8 in. pipes and larger. The new model included a total of 630 nodes. The study area is split into 41 sewersheds and 415 sub-sewersheds.

Using a $6 \mathrm{~h}$ inter-event time to split storm events, a total of 75 storm events that were $0.1 \mathrm{in} .(2.5 \mathrm{~mm})$ and larger were recorded during the flow monitoring activity. Out of these 75 storm events, 28 events had measurable RDII response in the flow meter data. Out of these 28 RDII events, 4 events (events number $13,15,16$ and 17) included snow melt conditions. Descriptions of the monitored storm events duration, total rain, and frequency are summarized in Table 1.4.

Table 1.4 Characteristics of monitored rain events with measurable RDII response.

\begin{tabular}{|c|c|c|c|c|}
\hline ID & Start Date and Time & Duration $(\mathrm{h})$ & Rain (in.) & Frequency \\
\hline 1 & $8 / 20 / 072: 30$ & 2.00 & 0.76 & 2-3 month \\
\hline 2 & $8 / 20 / 0715: 15$ & 7.33 & 1.56 & 9 month \\
\hline 3 & $8 / 22 / 075: 10$ & 4.17 & 1.5 & $1 \mathrm{y}$ \\
\hline 4 & $8 / 22 / 0718: 55$ & 0.25 & 0.38 & 3 month \\
\hline 5 & $8 / 25 / 07 \quad 17: 10$ & 0.50 & 0.27 & $<2$ month \\
\hline 6 & 9/8/07 12:20 & 10 & 0.85 & $2-3$ month \\
\hline 7 & 9/9/07 0:00 & 10.25 & 0.77 & $2-3$ month \\
\hline 8 & 9/27/07 5:50 & 6.92 & 0.97 & 2-3 month \\
\hline 9 & 10/22/07 17:50 & 36.17 & 3.6 & $5 \mathrm{y}$ \\
\hline 10 & 11/11/07 9:00 & 7.75 & 0.63 & $<2$ month \\
\hline 11 & $11 / 26 / 076: 15$ & 10.92 & 0.65 & $<2$ month \\
\hline 12 & $12 / 2 / 075: 00$ & 15.75 & 0.92 & $<2$ month \\
\hline 13 & 12/15/07 18:10 & 11.92 & 0.94 & $<2$ month \\
\hline 14 & 1/10/08 16:00 & 6.83 & 0.92 & 2 month \\
\hline 15 & 2/5/08 7:00 & 32.33 & 1.73 & 4 month \\
\hline 16 & 3/3/08 21:05 & 27.08 & 1.95 & 6-9 month \\
\hline 17 & 3/18/08 17:05 & 28.58 & 1.94 & 6-9 month \\
\hline 18 & $3 / 27 / 084: 40$ & 23.33 & 0.99 & $<2$ month \\
\hline 19 & 3/30/08 19:25 & 20.58 & 0.69 & $<2$ month \\
\hline 20 & 4/28/08 18:35 & 12.92 & 0.46 & $<2$ month \\
\hline 21 & $5 / 3 / 085: 40$ & 9.92 & 0.43 & $<2$ month \\
\hline 22 & $5 / 8 / 0816: 20$ & 4.25 & 0.44 & $<2$ month \\
\hline 23 & $5 / 11 / 086: 50$ & 18.83 & 0.78 & $<2$ month \\
\hline 24 & $6 / 3 / 0813: 10$ & 24.33 & 2.35 & $1-2 y$ \\
\hline 25 & $6 / 10 / 085: 45$ & 1.92 & 0.58 & 2 month \\
\hline 26 & $6 / 12 / 08$ 17:55 & 1.58 & 1.95 & $10 \mathrm{y}$ \\
\hline 27 & $6 / 13 / 08$ 17:45 & 1.83 & 0.81 & 3 month \\
\hline 28 & $6 / 14 / 085: 20$ & 1.08 & 1.31 & $2 y$ \\
\hline
\end{tabular}

Note: Events 13, 15, 16 and 17 (boldface) include snow melt effects. 


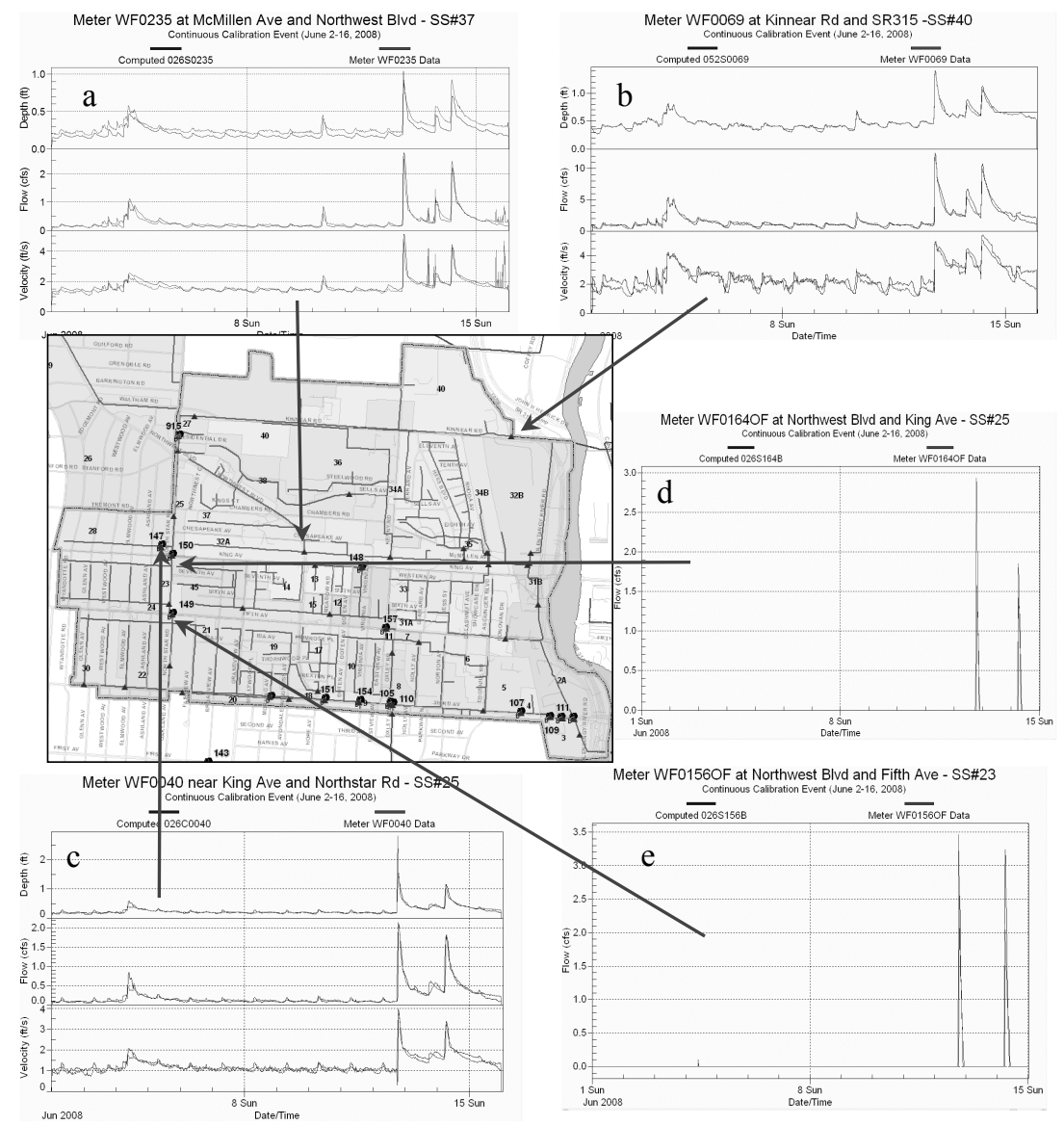

Figure 1.14 Calibration results at selected flow meter locations and overflow locations for the first two weeks of June 2008 storm events.

The proposed RDII procedure was used to calculate a single, constant set of RTK parameters per sewershed. As presented in Table 1.4, five storms took place in the first two weeks of June 2008. The last storm was a 2 y frequency storm which is expected to be precipitating over a fairly wet surface because of the previous $10 \mathrm{y}$ frequency storm that occurred two days beforehand. This storm meets the described procedure proposed in this chapter and was used to calculate a constant, single set of RTK parameters for each monitored sewershed. The $R, T$ and $K$ parameters for each triangle were calculated and calibrated to match the volume and shape of the monitored RDII hydrograph. In 
each sewershed, the generated RTK set from the June 14 event was used and applied to the entire monitoring period (August 2007-June 2008). Appropriate maximum storage and storage recovery rate parameters were calibrated for each sewershed to represent monthly abstraction conditions and to allow for calculating initial abstraction in a continuous calibration using SWMM4.4h model engine. Sample calibration results for the two weeks of June 2-16, 2008 are presented in Figure 1.14 above. Figures 1.14(a), (b) and (c) represented simulated depth, flow and velocity versus observed flow meter values. Figure 1.14(d) and (e) represent calibration results for two of the overflow locations.

Results for the entire monitoring period for flow meter WF0232 are represented in Figure 1.15. The observed flow is on the $x$-axis and the simulated flow is in the $y$-axis. Peak flow from each of the evaluated 28 events is plotted in the chart. The $45^{\circ}$ line represents the perfect match between observed and simulated. Dashed lines in the graph represent $\pm 10 \%$ discrepancy between observed and simulated peak flow.

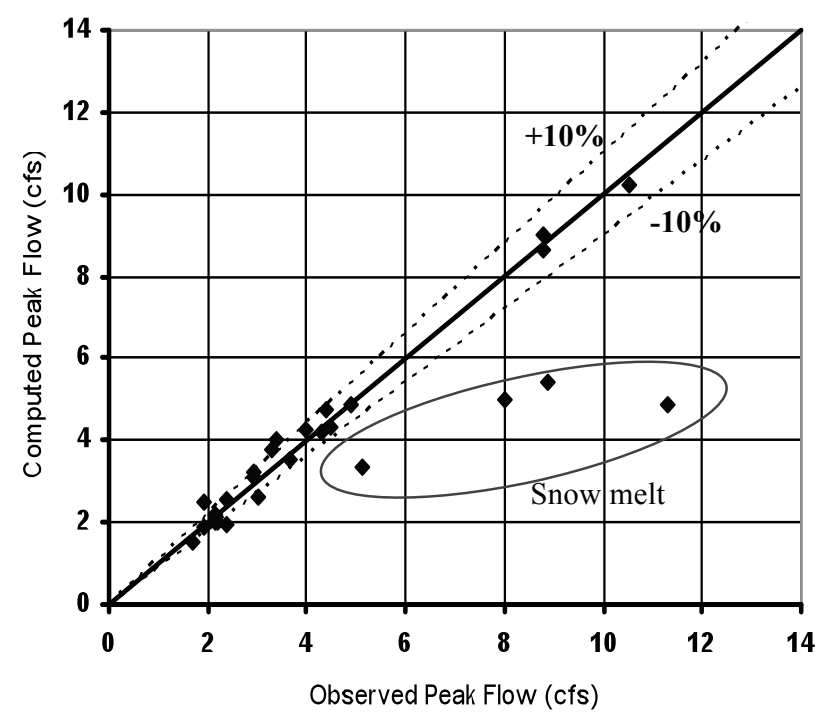

Figure 1.15 Peak flow calibration results for all 28 events between 08/01/2007 and 06/15/2008 at Meter WF0232.

Figure 1.15 demonstrates the accuracy of the calibrated model for the sewershed monitored by flow meter WF0232. Almost all events (especially the large peak flow ones) are within $\pm 10 \%$ from observed peak flows. 


\subsection{Conclusions}

The described stepped approach for continuous calibration is straightforward and produces accurate calibration results. The generated $R$ value is constant for each monitored basin. This $R$ value is absolute and gives a true indication of the collection system defects. It is not storm specific. This is due to the fact that there is no seasonal or AMC effect embedded in the $R$ values.

RDII parameters generated with this procedure can be applied with confidence to non-monitored storms since the effect of the initial abstraction and the recovery rate will be considered. Also, $R$ values generated from this procedure can confidently be used to compare RDII levels between sewersheds. This is true regardless of the flow monitoring data periods used to calibrate the different sewersheds.

Another important advantage of this procedure is the fact that it will ultimately lead to more accurate sizing for capital improvements. This is because the effect of initial abstraction is not ignored.

\section{References}

CIP 650405.9 Report: West Fifth Avenue Sanitary Sewer System Inflow and Infiltration Remediation Project

Czachorski, R. and Kacvinsky, G. Regulatory, Technical, and Modeling Challenges to Developing a Frequency Based SSO Control Project in Wayne County, Michigan, Central States Water Environment Association, 79th Annual Meeting, St. Charles, IL May 8-11, 2006.

Davis, M. and Merrill, S. Capacity Assurance Planning Environment for Wastewater Systems (CAPE), Brown and Caldwell, Inc, 1999.

Huber, W. and Dickinson, R. Storm Water Management Model Version 4, User's Manual, EPA/600/3 88/001a (NTIS PB88 236641/AS), EPA, Athens, GA, 1988.

Lai, F. Review of Sewer Design Criteria and RDII Prediction Methods, EPA/600/R08/010, 2008.

Vallabhaneni, S., Chan, C., and Burgess, E. Computer Tools for Sanitary Sewer System Capacity Analysis and Planning, EPA/600/R-07/111, 2007. 